\title{
Relationship between vascular age and classic cardiovascular risk factors and arterial stiffness
}

\author{
Maria Łoboz-Rudnicka ${ }^{1}$, Joanna Jaroch ${ }^{1}$, Zbigniew Bociąga ${ }^{1}$, Ewa Kruszyńska ${ }^{1}$, \\ Barbara Ciecierzyńska ${ }^{1}$, Magdalena Dziuba ${ }^{1}, \mathrm{Krzysztof} \mathrm{Dudek}^{2}$, \\ Izabela Uchmanowicz ${ }^{3}$, Krystyna Łoboz-Grudzieńn ${ }^{1,3}$ \\ ${ }^{1}$ Department of Cardiology, T. Marciniak Hospital, Wroclaw, Poland \\ ${ }^{2}$ Institute of Machine Design and Operation, Technical University of Wroclaw, Poland \\ ${ }^{3}$ Health Science Faculty, Wroclaw Medical University, Wroclaw, Poland
}

\begin{abstract}
Background: We aimed at establishing if the substitution of vascular age (VA) for chronological age (CA) causes a change in the Framingham Risk Score (FRS) categories. Sex differences in predictors of increased VA among cardiovascular (CV) risk factors and arterial stiffness (AS) parameters were identified.

Methods: In 187 asymptomatic subjects with CV risk factors, classified into 3 FRS categories the VA was derived from the nomograms of the carotid intima-media thickness. Two groups: 1 - subjects whose VA has exceeded CA for at least 5 years and 2 - others were established. Carotid AS parameters were obtained from echo-tracking.

Results: Substitution of VA for CA changed the FRS category into the higher one in $11.8 \%$ of subjects. Diabetes mellitus (DM) was the predictor of increased VA in both sexes, while metabolic syndrome (MS) only in women. The cut-off values of AS parameters that allow for prediction of increased VA were determined from the ROC-curve analysis - in men: $\beta>7.3$, $E p>103 \mathrm{kPa}, A C<0.61 \mathrm{~mm}^{2} / \mathrm{kPa}$ after adjustment for $D M, B M I>29.1 \mathrm{~kg} / \mathrm{m}^{2}, W H R>0.85$ and $C A>51$ years; in women: $\beta>9.6, E p>126 \mathrm{kPa}, A C<0.75 \mathrm{~mm}^{2} / \mathrm{kPa}, P W V-\beta>7.4 \mathrm{~m} / \mathrm{s}$ after adjustment for $D M, B M I>25.8 \mathrm{~kg} / \mathrm{m}^{2}, W H R>0.80$ and $C A>60$ years.

Conclusions: The substitution of VA for CA may increase the FRS category. Sex differences in predictors of increased VA were identified. AS parameters proved to be predictors of increased VA besides the classic risk factors. (Cardiol J 2013; 20, 4: 394-401)
\end{abstract}

Key words: vascular age, Framingham Risk Score, arterial stiffness

\section{Introduction}

Risk algorithms, mostly based on the analysis of the chronological age (CA) and classic cardiovascular $(\mathrm{CV})$ risk factors, have limitations in the precise CV risk assessment of an individual and may cause underestimation of subjects, in whom aggressive modification of $\mathrm{CV}$ disease risk factors should be introduced [1,2]. Therefore, the concept of evaluating the "vascular age" (VA) — that would reflect the real atherosclerotic damage - has recently drawn a growing attention in the field of the CV risk assessment [3-6]. VA can be investigated by either imaging modalities like ultrasonic measu-

Address for correspondence: Maria Łoboz-Rudnicka, Department of Cardiology, T. Marciniak Hospital, ul. Traugutta 116, 50-420 Wrocław, Poland, tel/fax: +48 7134273 05, e-mail: marialoboz@o2.pl

Received: 20.11.2012

Accepted: 14.12.2012 
rement of carotid intima-media thickness (CIMT) and plaque detection or by, so called, physiological methods like pulse wave velocity (PWV) and pulse wave analysis that reflect the arterial stiffness (AS) [7]. AS can be considered a measure of the cumulative influence of $\mathrm{CV}$ risk factors with aging on arterial tree and may be regarded as a tissue biomarker [6-8].

We tested the hypothesis that the Framingham Risk Score (FRS) based on traditional CV risk factors does not identify subjects whose VA exceeds the CA for at least 5 years. We aimed at establishing whether the substitution of the VA for the CA in the FRS will cause the change in risk categories, the so called "reclassification". We investigated which of the traditional $\mathrm{CV}$ risk factors enable to predict that the VA exceeds the CA for at least 5 years and establish if there are any sex-specific differences. We examined the relationship between the AS indices and the VA.

\section{Methods}

The study group consisted of 187 subjects (mean CA: 53.8 years [52.1-55.5]): 101 women (mean CA: 55.0 years [52.7-57.2]) and 86 men (mean CA: 52.4 years [49.9-54.9]) with CV risk factors and without history of manifest CV disease (coronary, peripheral and cerebral vascular disease was excluded).

The data concerning medical history of the study population, their risk factors, family history of $\mathrm{CV}$ disease and current pharmacological medication was obtained with the use of a questionnaire. Laboratory tests were performed, including: fasting glucose serum level and lipids (total cholesterol, low-density lipoprotein cholesterol [LDL-C], high-density lipoprotein cholesterol [HDL-C], triglycerides) serum level.

All study participants were classified into three FRS risk categories: low $(<6 \%)$, intermediate (6-20\%) and high (> 20\%) according to the 10-year Framingham General Cardiovascular Disease Risk algorithm. The algorithm takes into account the following factors: CA, total cholesterol serum level, HDL-C serum level, the value of systolic blood pressure (with regard if it is treated or not), current smoking and diabetes mellitus (DM) [9].

Metabolic syndrome (MS) was defined according to the IDF definition [10].

The B-mode ultrasound measurement of the mean CIMT was performed with Aloka ProSound Alpha 10 machine in accordance with the Mannheim Protocol recommendations [11]. The VA was determined with the use of the regression model in accordance with the concept of JH Stein who used the gender- and race-specific nomograms of the distribution of the CIMT values in different age groups (the nomograms were derived from the Atherosclerosis Risk in Communities Study) and defined the VA as "the age at which the composite CIMT value for an individual of a given race and gender would represent the median value (50 ${ }^{\text {th }}$ percentile)" $[12-14]$.

The AS parameters were calculated with the application of the high-resolution echo-tracking (eT) system incorporated in Aloka ProSound Alpha 10 machine. After obtaining a clear image of the intima-media complex of both anterior and posterior wall of the right common carotid artery (CCA) in its longitudinal axis, the eT gate for the measurement of arterial diameter changes along the cardiac cycle was positioned at the boundaries between the intima and media of the anterior and posterior wall of the right CCA, $1-2 \mathrm{~cm}$ proximal to the bifurcation [15]. The proper identification of the stages of the cardiac cycle was provided by the ECG monitoring. The systolic and diastolic blood pressure entered into the system was measured during the eT procedure (the patient in a supine position for at least $15 \mathrm{~min}$ ) at the left brachial artery. Three to five beats were averaged to obtain a representative waveform. The following AS parameters were calculated automatically [16]:

$-\beta$ - beta, beta stiffness index [U]:

$\beta=\ln (\mathrm{Ps} / \mathrm{Pd}) /[(\mathrm{Ds}-\mathrm{Dd}) / \mathrm{Dd}]$;

- Ep - Peterson's modulus [kPa]:

$\mathrm{Ep}=(\mathrm{Ps}-\mathrm{Pd}) /[(\mathrm{Ds}-\mathrm{Dd}) / \mathrm{Dd}] ;$

- AC - arterial compliance $\left[\mathrm{mm}^{2} / \mathrm{kPa}\right]$ :

$\mathrm{AC}=\pi(\mathrm{Ds} \times \mathrm{Ds}-\mathrm{Dd} \times \mathrm{Dd}) /[4 \times(\mathrm{Ps}-\mathrm{Pd})] ;$

- PWV- $\beta$-one-point pulse wave velocity $[\mathrm{m} / \mathrm{s}]$ : PWV $-\beta=\sqrt{ }(\beta \times$ Ps $/ 2 \times \rho)$,

where: $\ln$ - the natural logarithm, Ps - systolic blood pressure, $\mathrm{Pd}$ - diastolic blood pressure, Ds — arterial systolic diameter, $\mathrm{Dd}$ - arterial diastolic diameter, $\rho$ - blood density $\left(1.050 \mathrm{~kg} / \mathrm{m}^{3}\right)$ (Fig. 1 ).

Reproducibility of these measurements has been reported elsewhere [17].

All participants provided written informed consent. The study was approved by the ethics committee of Medical University of Wroclaw.

\section{Statistical analysis}

The statistical analysis of the collected results has been performed using the software package STATISTICA v.9. The analysis included: for quantitative features - accuracy of normal distribution has been verified with Shapiro-Wilk's and $\chi^{2}$ tests, 


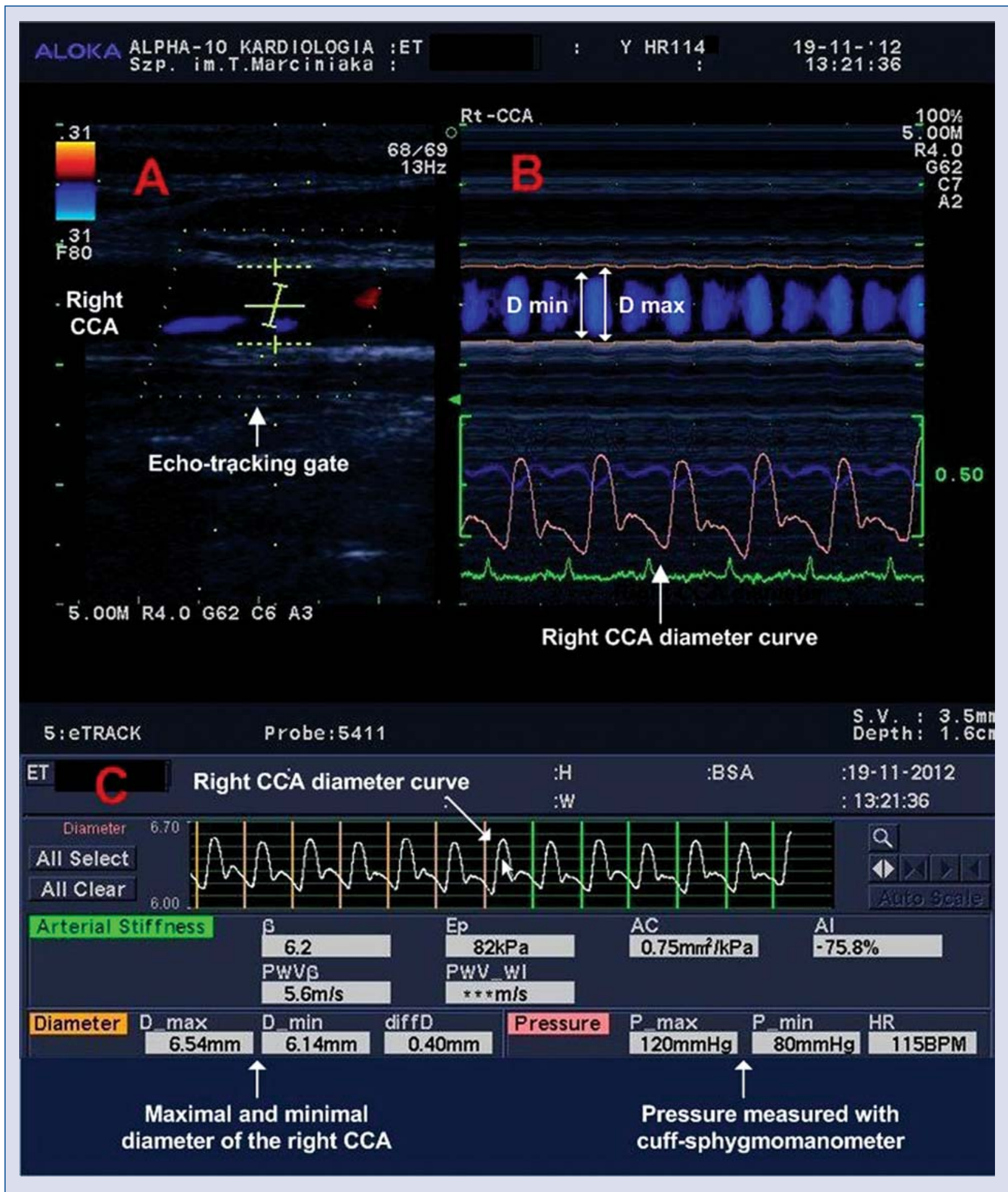

Figure 1. Measurement of arterial stiffness parameters with echo-tracking; A. Positioning of the echo-tracking gate in the right common carotid artery (CCA); B. The curve of the right CCA diameter changes obtained with the echo-tracking system; D min - minimal arterial diameter; D max - maximal arterial diameter; C. Arterial stiffness parameters: $\beta$ - beta stiffness index; Ep — Peterson's modulus; AC — arterial compliance; $\mathrm{Al}$ - augmentation index; PWV- $\beta$ - one-point pulse wave velocity; PWV_WI — pulse wave velocity wave intensity.

basic statistics have been calculated (mean, 95\% confidence interval [CI]); for qualitative (nominal) features - occurrence frequency (fractions) has been calculated; significance of differences between means in two groups (differed in sex or differed in calendar age CA and vascular age VA) 
Table 1. Patient clinical characteristics.

\begin{tabular}{|c|c|c|c|c|}
\hline & Women $(n=101)$ & Men $(n=86)$ & Total $(n=187)$ & $\mathbf{P}$ \\
\hline Chronological age [years] & $55.0(52.7-57.2)$ & $52.4(49.9-54.9)$ & $53.8(52.1-55.5)$ & 0.129 \\
\hline Hypertension & $47(46.5 \%)$ & $45(52.3 \%)$ & $92(49.2 \%)$ & 0.520 \\
\hline Diabetes mellitus type 2 & $37(36.6 \%)$ & $46(53.5 \%)$ & $83(44.4 \%)$ & 0.030 \\
\hline Smoking & $35(34.7 \%)$ & $36(41.9 \%)$ & $71(38.0 \%)$ & 0.389 \\
\hline Hypercholesterolemia & $63(62.4 \%)$ & $53(61.6 \%)$ & $116(62.0 \%)$ & 0.963 \\
\hline Metabolic syndrome & $48(47.5 \%)$ & $15(17.4 \%)$ & $37(33.7 \%)$ & $<0.001$ \\
\hline Heart rate $\left[\mathrm{min}^{-1}\right]$ & $73.4(71.5-75.3)$ & $68.7(66.6-70.8)$ & $71.2(69.8-72.7)$ & 0.001 \\
\hline Systolic BP [mm Hg] & 132 (128-136) & 133 (130-136) & 133 (130-135) & 0.354 \\
\hline Diastolic BP [mm Hg] & 77 (75-79) & 75 (73-77) & $76(74-77)$ & 0.181 \\
\hline Pulse pressure [mm Hg] & $55(52-59)$ & $59(56-61)$ & $57(55-59)$ & 0.026 \\
\hline Fasting glucose [mg/dL] & 97 (94-101) & $100(95-105)$ & $98(95-101)$ & 0.403 \\
\hline Total cholesterol [mg/dL] & $217(208-226)$ & 205 (196-213) & $211(205-217)$ & 0.082 \\
\hline LDL-C [mg/dL] & $129(121-137)$ & $127(119-135)$ & $128(122-134)$ & 0.942 \\
\hline $\mathrm{HDL}-\mathrm{C}[\mathrm{mg} / \mathrm{dL}]$ & $62(58-65)$ & $50(47-53)$ & $56(54-59)$ & $<0.001$ \\
\hline Triglycerides[mg/dL] & 150 (132-169) & 146 (126-165) & $148(135-161)$ & 0.704 \\
\hline $\begin{array}{l}\text { Total/high density } \\
\text { lipoprotein ratio }\end{array}$ & $3.76(3.51-4.00)$ & $4.38(4.06-4.69)$ & $4.04(3.84-4.24)$ & $<0.001$ \\
\hline Body mass index $\left[\mathrm{kg} / \mathrm{m}^{2}\right]$ & $27.9(26.9-29.0)$ & 28.8 (27.9-29.7) & $28.3(27.7-29.0)$ & 0.128 \\
\hline Waist circumference $[\mathrm{cm}]$ & $87(84-91)$ & 102 (98-106) & $93(90-96)$ & $<0.001$ \\
\hline Waist to hips ratio & $0.82(0.80-0.84)$ & $0.94(0.92-0.97)$ & $0.87(0.85-0.89)$ & $<0.001$ \\
\hline FRS [\%] & $11.1(9.3-13.0)$ & $20.4(18.1-22.7)$ & $15.4(13.8-17.0)$ & $<0.001$ \\
\hline FRS category low & $30(29.7 \%)$ & $10(11.6 \%)$ & $40(21.4 \%)$ & 0.005 \\
\hline FRS category intermediate & $48(47.5 \%)$ & $29(33.7 \%)$ & $77(41.2 \%)$ & 0.078 \\
\hline FRS category high & $23(22.8 \%)$ & $47(54.7 \%)$ & $70(37.4 \%)$ & $<0.001$ \\
\hline
\end{tabular}

BP — blood pressure; LDL-C — low density lipoprotein cholesterol; HDL-C — high density lipoprotein cholesterol; FRS — Framingham Risk Score

has been verified with Mann-Whitney's nonparametric test or t-test for independent variables; significance of differences in occurrence frequency of specified nominal or categorized variables subgroups has been verified with Pearson's $\chi^{2}$ test or with Fisher's exacts test. Both values of odds ratio and their $95 \% \mathrm{CI}$ have been estimated. For quantitative variables that showed a statistically significant difference between the two groups, receiver-operating characteristic (ROC) curves were obtained to calculate the cut-off values optimized to reach the best compromise in the prediction of the increased VA. Optimal cut-off was defined as a threshold where the sum of sensitivity and specificity was maximum. Value $\mathrm{p}<0.05$ has been accepted as a critical level for all statistical tests.

\section{Results}

The detailed patient clinical characteristics have been presented in Table 1 . The prevalence of the traditional CV risk factors like: hypertension, smoking and hypercholesterolemia did not differ between men and women, while DM occurred more frequently in men and MS in women.

\section{Framingham Risk Score: Reclassification}

The 10-year FRS was higher in men than in women $(20.4 \%$ vs. $11.1 \%, \mathrm{p}<0.001)$ and the analysis of the risk categories revealed that more women than men were classified in a low-risk group $(29.7 \%$ vs. $11.6 \%, p=0.005)$, while more men - in comparison to women - belonged to a high-risk group $(54.7 \%$ vs. $22.8 \%$, p $<0.001)$. The mean VA of the whole population significantly exceeded the mean CA (59.9 years; $56.0-63.8$ vs. 53.8 years; $52.1-55.5 ; \mathrm{p}<0.05)$, and the mean difference value was about 6.1 years. An analogous trend, even more pronounced, was observed in men (61.9 years; $56.5-67.4$ vs. 52.4 years; $49.9-54.9 ; \mathrm{p}<0.001)$, with a mean difference about 9.5 years. In women the difference between VA and CA did not reach the statistical significance.

The study material was divided into two groups: group 1 -individuals whose VA exceeded 
Table 2. Relationship between the Framingham Risk Score (FRS) categories and vascular age.

\begin{tabular}{|c|c|c|c|c|c|c|}
\hline \multirow[t]{2}{*}{ FRS category } & \multicolumn{2}{|c|}{ Men $(n=86)$} & \multicolumn{2}{|c|}{ Women $(n=101)$} & \multicolumn{2}{|c|}{ Total $(n=187)$} \\
\hline & $\begin{array}{c}\text { Group } 1 \\
\text { VA-CA } \geq 5 \\
N=47\end{array}$ & $\begin{array}{c}\text { Group } 2 \\
\text { Others } \\
\mathbf{N}=39\end{array}$ & $\begin{array}{c}\text { Group } 1 \\
\text { VA-CA } \geq 5 \\
N=38\end{array}$ & $\begin{array}{c}\text { Group } 2 \\
\text { Others } \\
N=63\end{array}$ & $\begin{array}{c}\text { Group } 1 \\
\text { VA-CA } \geq 5 \\
N=85\end{array}$ & $\begin{array}{c}\text { Group } 2 \\
\text { Others } \\
N=102\end{array}$ \\
\hline Low & $6(12.8 \%)$ & $4(10.3 \%)$ & $11(28.9 \%)$ & $19(30.2 \%)$ & $17(20.0 \%)$ & $23(22.5 \%)$ \\
\hline Intermediate & $12(25.5 \%)$ & $17(43.6 \%)$ & $17(44.7 \%)$ & $31(49.2 \%)$ & $29(34.1 \%)$ & $48(47.1 \%)$ \\
\hline \multirow[t]{2}{*}{ High } & $29(61.7 \%)$ & $18(46.2 \%)$ & $10(26.3 \%)$ & $13(20.6 \%)$ & $39(45.9 \%)$ & $31(30.4 \%)$ \\
\hline & \multicolumn{2}{|c|}{$\begin{array}{c}\chi^{2} \text { test: } \\
\chi^{2}=3.12 ; \mathrm{df}=2 ; \mathrm{p}=0.210\end{array}$} & \multicolumn{2}{|c|}{$\begin{aligned} & \chi^{2} \text { test: } \\
\chi^{2}=0.45 ; & \text { df }=2 ; p=0.800\end{aligned}$} & \multicolumn{2}{|c|}{$\begin{array}{c}\chi^{2} \text { test: } \\
\chi^{2}=4.60 ; \mathrm{df}=2 ; \mathrm{p}=0.100\end{array}$} \\
\hline
\end{tabular}

VA - vascular age; CA - chronological age

Table 3. Reclassification - change of the Framingham Risk Score (FRS) category into the higher one after the substitution of the vascular age for the chronological age.

\begin{tabular}{|c|c|c|c|c|c|c|c|c|}
\hline & Total $(n=187)$ & \multicolumn{3}{|c|}{ Men $(n=86)$} & \multicolumn{3}{|c|}{ Women $(n=101)$} & $\mathbf{P}$ \\
\hline Calendar age [years] & $53.8(52.1-55.5)$ & \multicolumn{3}{|c|}{$52.4(49.9-54.9)$} & \multicolumn{3}{|c|}{$55.0(52.7-57.2)$} & 0.129 \\
\hline Vascular age [years] & $59.9(56.0-63.8)$ & \multicolumn{3}{|c|}{$61.9(56.5-67.4)$} & \multicolumn{3}{|c|}{$58.1(52.5-63.6)$} & 0.202 \\
\hline \multirow[t]{3}{*}{ Reclassification } & $22(11.8 \%)$ & \multicolumn{3}{|c|}{$16(18.6 \%)$} & \multicolumn{3}{|c|}{$6(5.9 \%)$} & 0.0142 \\
\hline & & $\begin{array}{l}\text { Group } 1 \\
(n=47)\end{array}$ & $\begin{array}{l}\text { Group } 2 \\
(\mathrm{n}=39)\end{array}$ & $\mathbf{P}$ & $\begin{array}{l}\text { Group } 1 \\
(n=38)\end{array}$ & $\begin{array}{l}\text { Group } 2 \\
\text { (n=63) }\end{array}$ & $\mathbf{P}$ & \\
\hline & & $15(31.9 \%)$ & $1(2.6 \%)$ & 0.0005 & $6(15.8 \%)$ & $0(0 \%)$ & 0.0022 & \\
\hline $\begin{array}{l}\text { FRS category } \\
\text { low } \rightarrow \text { intermediate }\end{array}$ & 9 & $4(8.5 \%)$ & $1(2.6 \%)$ & & $4(10.5 \%)$ & 0 & & \\
\hline $\begin{array}{l}\text { FRS category } \\
\text { intermediate } \rightarrow \text { high }\end{array}$ & 13 & $11(23.4 \%)$ & 0 & & $2(5.3 \%)$ & 0 & & \\
\hline
\end{tabular}

the CA for at least 5 years, and group 2 - others, separately for sex. To group 1 belonged $85(45 \%)$ subjects: $47(55 \%)$ men and $38(38 \%)$ women. The statistical analysis revealed that men belonged to group 1 more frequently than women $(\mathrm{p}=0.029)$.

The important observation was that in both sexes the FRS category did not differentiate between individuals who belonged to group 1 and to group 2 (Table 2).

The upgrade into the higher $\mathrm{CV}$ risk category - the so called "reclassification" occurred in 22 subjects (11.8\% of the whole population; Table 3 ). The sex analysis revealed that men underwent reclassification more frequently than women $(18.6 \%$ vs. $5.9 \%, p=0.0142)$; Twenty one $(95 \%)$ of the individuals who underwent reclassification belonged to group 1.

\section{Predictors of subjects in whom the}

VA exceeded the CA for at least 5 years:

Sex differences

The analysis of the predictors of the VA exceeding the CA for at least 5 years performed separately for men and women revealed that DM was a predictor in both sexes, although a stronger one in women (women: OR 3.63, p = 0.005; men: OR 2.54, $\mathrm{p}=0.058$ ). To the additional predictors in women belonged: MS (OR 4.01, $\mathrm{p}=0.009$ ), waist to hip ratio (WHR) $>0.80(\mathrm{OR} 17.3, \mathrm{p}=0.003)$ and body mass index (BMI) $>25.8$ (OR 3.52, $\mathrm{p}=$ $=0.012$; Table 4$)$. The cut-off values were determined from the ROC curve.

\section{Relationships between arterial stiffness parameters and vascular age}

The AS parameters in men, except for the arterial compliance, showed linear correlation with the CA. In women almost all AS parameters correlated positively linearly with the VA (except for the arterial compliance that showed negative correlation), while in men it was only $\beta$ and $\mathrm{Ep}$ (Table 5).

The cut-off values of the AS parameters that allow for the prediction of increased VA were determined from the ROC-curve analysis (Table 6). Of noteworthy is that the cut-off values in men were lower than in women. 
Table 4. Predictors of the vascular age exceeding the chronological age for at least 5 years in men and women.

\begin{tabular}{|c|c|c|c|c|}
\hline & \multicolumn{2}{|c|}{ Men $(n=86)$} & \multicolumn{2}{|c|}{ Women $(n=101)$} \\
\hline & $\mathbf{P}^{\mathbf{a}}$ & OR $(95 \% \mathrm{Cl})$ & $\mathbf{P}^{\mathbf{a}}$ & OR $(95 \% \mathrm{Cl})$ \\
\hline Hypertension & 0.694 & $1.30(0.56-3.05)$ & 0.940 & $0.89(0.40-2.00)$ \\
\hline Diabetes mellitus & 0.058 & $2.54(1.06-6.07)$ & 0.005 & $3.63(1.54-8.53)$ \\
\hline Smoking & 0.606 & $0.72(0.31-1.71)$ & 0.249 & $0.54(0.22-1.31)$ \\
\hline Metabolic syndrome & 0.863 & $1.30(0.42-4.05)$ & 0.009 & $4.01(1.49-10.8)$ \\
\hline Hypercholesterolemia & 0.836 & $0.83(0.34-1.98)$ & 0.174 & $0.52(0.23-1.18)$ \\
\hline WHR $>0.93^{b}$ & 0.076 & $4.00(1.06-15.1)$ & & \\
\hline WHR $>0.80^{\mathrm{b}}$ & & & 0.003 & $17.3(2.10-143)$ \\
\hline $\mathrm{BMI}>29.1 \mathrm{~kg} / \mathrm{m}^{2 \mathrm{c}}$ & 0.319 & $1.71(0.72-4.08)$ & & \\
\hline $\mathrm{BMI}>25.8 \mathrm{~kg} / \mathrm{m}^{2 \mathrm{c}}$ & & & 0.012 & $3.52(1.39-8.87)$ \\
\hline
\end{tabular}

${ }^{\mathrm{a}} \chi^{2}$ test; ${ }^{b}$ the cut-off value from the ROC curve: for men AUC $=0.627$, for women $A U C=0.662 ;{ }^{c}$ the cut-off value from the ROC curve: for men $A U C=0.553$, for women $A U C=0.624 ; \mathrm{OR}$ - odds ratio; $\mathrm{Cl}$ - confidence interval; WHR - waist to hips ratio; $\mathrm{BMI}$ - body mass index

Table 5. Linear correlation between arterial stiffness parameters and chronological and vascular age in men and women.

\begin{tabular}{|c|c|c|c|c|c|c|c|c|}
\hline & \multicolumn{4}{|c|}{ Men } & \multicolumn{4}{|c|}{ Women } \\
\hline & $\beta$ & Ep & $A C$ & $\mathbf{P W V}-\beta$ & $\beta$ & Ep & AC & PWV- $\beta$ \\
\hline CA & $r=0.420$ & $r=0.398$ & $r=-0.180$ & $r=0.391$ & $r=0.416$ & $r=0.441$ & $r=-0.379$ & $r=0.484$ \\
\hline & $p<0.001$ & $p<0.001$ & $p=0.096$ & $p=0.001$ & $p<0.001$ & $p<0.001$ & $p<0.001$ & $p<0.001$ \\
\hline VA & $\begin{array}{l}r=0.304 \\
p=0.005\end{array}$ & $\begin{array}{l}r=0.320 \\
p=0.003\end{array}$ & $\begin{array}{l}r=-0.048 \\
p=0.661\end{array}$ & $\begin{array}{l}r=0.150 \\
p=0.167\end{array}$ & $\begin{array}{l}r=0.593 \\
p<0.001\end{array}$ & $\begin{array}{l}r=0.538 \\
p<0.001\end{array}$ & $\begin{array}{l}r=-0.229 \\
p=0.022\end{array}$ & $\begin{array}{l}r=0.421 \\
p<0.001\end{array}$ \\
\hline
\end{tabular}

CA - chronological age; VA — vascular age; $\beta$ - beta stiffness index; Ep — Peterson's modulus; AC — arterial compliance; PWV- $\beta$ - one-point pulse wave velocity

Table 6. The cut-off values of the arterial stiffness parameters in prediction of the vascular age exceeding the chronological age for at least 5 years.

\begin{tabular}{|c|c|c|c|c|c|}
\hline \multicolumn{3}{|c|}{ Men } & \multicolumn{3}{|c|}{ Women } \\
\hline Stiffness parameters & $\mathbf{P}^{\mathbf{a}}$ & Odds ratiob & Stiffness parameters & $\mathbf{P}^{\mathbf{a}}$ & Odds ratio ${ }^{c}$ \\
\hline$\beta>7.3$ & 0.0003 & $6.46(4.07-10.2)$ & $\beta>9.6$ & 0.0001 & $6.92(4.34-11.0)$ \\
\hline $\mathrm{Ep}>103 \mathrm{kPa}$ & 0.0199 & $3.00(1.98-4.56)$ & Ep $>126$ & 0.0032 & $4.38(2.86-6.71)$ \\
\hline $\mathrm{AC}<0.61 \mathrm{~mm}^{2} / \mathrm{kPa}$ & 0.0463 & $2.81(1.85-4.26)$ & $\mathrm{AC}<0.75 \mathrm{~mm}^{2} / \mathrm{kPa}$ & 0.0439 & $2.76(1.83-4.16)$ \\
\hline $\mathrm{PWV}-\beta>6.0 \mathrm{~m} / \mathrm{s}$ & 0.0627 & $2.43(1.61-3.68)$ & $\mathrm{PWV}-\beta>7.4 \mathrm{~m} / \mathrm{s}$ & 0.0103 & $4.28(2.62-6.99)$ \\
\hline
\end{tabular}

${ }^{\mathrm{a}} \chi^{2}$ test; ${ }^{\mathrm{b}}$ adjusted odds ratio for diabetes, chronological age $>51$ years; WHR $>0.85$ and BMI $>29.1 \mathrm{~kg} / \mathrm{m}^{2}$; ${ }^{\mathrm{c}}$ adjusted odds ratio for diabetes, chronological age $>60$ years, WHR $>0.80$ and $\mathrm{BMI}>25.8 \mathrm{~kg} / \mathrm{m}^{2} ; \beta$ - beta stiffness index; Ep - Peterson's modulus; AC - arterial compliance; PWV- $\beta$ - one-point pulse wave velocity

\section{Discussion}

Nowadays we are witnessing the revival of the idea: "a man is as old as his arteries" in the concept of the "vascular age" [3-7, 13, 14, 18].

\section{Framingham Risk Score: Reclassification}

FRS is useful in the population risk assessment but is not helpful in the individual risk evaluation.
Various reports have provided evidence that atherosclerosis in form of increased CIMT, plaques and coronary artery calcium score $>0$ can be found in asymptomatic subjects classified as at low - or intermediate CV risk [19, 20]. Framingham CV risk estimates are influenced strongly by the $\mathrm{CA}$. Integrating VA in the risk algorithms could be an attractive concept for subjects whose risk was estimated as low or intermediate according to 
the traditional risk scores. In our study the FRS categories did not differentiate between individuals with increased VA and others - the finding consistent with the previous studies [19, 20]. Our results confirmed the thesis that VA represents the atherosclerotic burden which varies between individuals with the same CA despite similar CV risk profiles [18].

In our study $11.8 \%$ of the population was reclassified into the higher FRS category after substitution of VA for CA. In the report by Stein et al. [13] the proportion of subjects who underwent reclassification into the higher risk category was comparable (15\%). We observed a stronger tendency for reclassification in men. This finding was consistent with the results of the study by Gepner et al. [21] performed on a population of asymptomatic and non-diabetic subjects, in which the male sex belonged to the predictors of the rise in $\mathrm{CV}$ risk for at least $5 \%$. This shows that the assessment of the VA helps identify individuals whose CV risk might be underestimated.

\section{Predictors of the VA exceeding the CA for at least 5 years: Sex differences}

The present study revealed a few interesting issues concerning sex differences in predictors of the VA exceeding the CA for at least 5 years. First of all, in our population DM was the only predictor of increased VA common for both men and women (with a stronger influence in females). One of the possible mechanisms that accounts for elevated CV risk and increased VA in individuals with abnormal glucose metabolism leads through increased AS [22]. Then, MS and its components: elevated BMI and WHR were proved to be predictive for increased VA only in females. This could be partly explained by the fact that our female population belonged mainly to the middle-aged group (perimenopausal women) - which is characterized by the clustering of various risk factors. It has been shown in literature that the effect of MS on the development of early atherosclerosis usually expressed by thickened CIMT is more pronounced in women than in men. There have already been a few reports providing evidence that MS accelerates the age-dependent increase in CIMT and AS parameters and that its influence on vascular structure and function is independent of its individual components and results mainly from the clustering of risk factors [23, 24].

In the present study no association between the HDL-C or LDL-C serum levels and VA was established, which might be caused by the fact that
$6 \%$ of the study population was on lipid-lowering therapy. In the report by Stein et al. [13] HDL-C and LDL-C serum levels were proved to be predictors of the upgrade of the coronary heart disease risk category into the higher one.

The surprising finding of our study was that systolic blood pressure was not a predictor of the VA exceeding the CA for at least 5 years. In the report by Stein et al. [13] systolic blood pressure was proved to be a weak predictor of increased VA (of noteworthy is that in the study by Stein et al. [13] increased VA was the VA exceeding the CA for at least 10 years).

Relationships between AS parameters and VA

Vascular stiffening is an integral part of the "normal" vascular aging. It is mainly caused by the degeneration of elastic lamellae and overproduction of abnormal collagen in the arterial wall [25].

O'Rourke [26] suggests that atherosclerosis should be evaluated in 2 aspects: atherosis which reflects structural changes of the arterial wall and sclerosis - concerned with functional changes. CIMT is a marker of atherosis, while AS reflects sclerosis. The novel high resolution eT method enables simple, noninvasive assessment of the $\mathrm{AS}$ and it correlates with the carotid-femoral PWV, which is a gold standard in the assessment of the AS [8].To our best knowledge, this the first report concerned with the relationship between AS measured by eT and VA.

In our study AS parameters measured at the CCA correlated with the CA, the finding that was consistent with the literature [27]. One of the strengths of our study was the investigation of the relationship between the AS parameters and CIMT-derived VA. Our novel approach enabled an integrated evaluation of the structural and functional arterial changes. We proved that AS parameters correlated with the VA. Furthermore, we identified the cut-off values of some of the AS parameters that allowed for the prediction of the VA exceeding the CA for at least 5 years (from the ROC curve after adjustment for other risk factors such as: DM, BMI, WHR and CA).

As it was mentioned earlier, AS reflects the process of the physiological vascular aging. However, it can be accelerated by variable damaging factors that interact with the vascular wall throughout the whole life of an individual. The measurement of the AS parameters provides the information on the present condition of the arterial wall. Therefore, the assessment of AS parameters can be a good method for the evaluation of the VA. 


\section{Limitations of the study}

The present study has an observational, cross-sectional design. The sample was entirely Caucasian. The AS parameters were calculated from algorithms that include the change in CCA diameter and the value of blood pressure measured at the brachial artery not at the CCA, which may affect the measurement of the AS parameters because carotid and brachial pressure is not identical due to the phenomenon of the central to peripheral blood pressure amplification, pronounced especially in young people. Our sample consisted mostly of middle-aged subjects. Because there was no follow-up of the study population, the relationships between the study results and subsequent $\mathrm{CV}$ events remains unknown. The significance of the estimation of the VA is still unclear.

\section{Conclusions}

The substitution of the VA for the CA may cause the change of the FRS category into the higher one. There are sex-related differences in predictors of increased VA. AS parameters proved to be predictors of increased VA besides the classic risk factors. The results of our study suggest that integrative approach to $\mathrm{CV}$ risk assessment - that incorporates markers of structural and functional vascular parameters into risk algorithms - might be beneficial. Future studies will be needed to establish the prognostic value of VA.

\section{Acknowledgements}

The study was supported by the Grant of Polish Cardiac Society and Servier - 2009.

\section{Conflict of interest: none declared}

\section{References}

1. Greenland P, Alpert JS, Beller GA et al. 2010 ACCF/AHA Guideline for Assessment of Cardiovascular Risk in Asymptomatic Adults : A Report of the American College of Cardiology Foundation/American Heart Association Task Force on Practice Guidelines. Circulation, 2010; 122: e584-e636; J Am Coll Cardiol, 2010; 56: e50-e103.

2. Perk J, De Backer G, Gohlke H et al. European Guidelines on cardiovascular disease prevention in clinical practice (version 2012). The Fifth Joint Task Force of the European Society of Cardiology and Other Societies on Cardiovascular Disease Prevention in Clinical Practice.. Eur Heart J, 2012; 33:1635-1701.

3. Najjar SS, Scuteri A, Lakatta EG. Arterial aging: is it an immutable cardiovascular risk factor? Hypertension, 2005; 46: 454-462.

4. Lakatta EG, Levy D. Arterial and cardiac aging: Major shareholders in cardiovascular disease enterprises: Part I: Aging arteries: A 'Set Up” for Vascular Disease. Circulation, 2003; 107: 139-146.

5. Nilsson PM, Boutouyrie P, Laurent S. Vascular aging: A tale of EVA and ADAM in cardiovascular risk assessment and prevention. Hypertension, 2009; 54: 3-10.
6. Nilsson PM, Lurbe E, Laurent S. The early life origins of vascular aging and cardiovascular risk: the EVA syndrome. J Hypertens, 2008; 26: 1049-1057.

7. Nilsson PM. Early vascular aging (EVA): Consequences and prevention. Vascular Health Risk Management, 2008; 4: 547-552.

8. Laurent S, Cockcroft J, Van Bortel L et al. Expert consensus document on arterial stiffness: methodological issues and clinical applications. Eur Heart J, 2006; 27: 2588-2605.

9. D’Agostino RB Sr, Vasan RS, Pencina MJ et al. General cardiovascular risk profile for use in primary care: The Framingham Heart Study. Circulation, 2008; 117: 743-753.

10. The IDF consensus worldwide definition of the metabolic syndrome. http://www.idf.org/webdata/docs/MetS_def_update2006.pdf.

11. Touboul PJ, Hennerici MG, Meairs S et $\overline{\mathrm{al}}$. Mannheim carotid intima-media thickness consensus (2004-2006). An update on behalf of the Advisory Board of the $3^{\text {rd }}$ and $4^{\text {th }}$ Watching the Risk Symposium, $13^{\text {th }}$ and $15^{\text {th }}$ European Stroke Conferences. Mannheim, Germany, 2004, and Brussels, Belgium, 2006. Cerebrovasc Dis, 2007; 23: 75-80.

12. Howard G, Sharrett AR, Heiss G et al. Carotid artery intimal-medial thickness distribution in general populations as evaluated by B-mode ultrasound ARIC Investigators. Stroke, 1993; 24: 1297-1304.

13. Stein JH, Fraizer MC, Aeschlimann SE, Nelson-Worel J, McBride PE, Douglas PS. Vascular age: Integrating carotid intima-media thickness measurements with global coronary risk assessment. Clin. Cardiol, 2004; 27: 388-392.

14. Stein JH. Carotid intima thickness and vascular age: You are only as old as your arteries look. J Am Soc Echocardiogr, 2004; 17: 686-689.

15. Vriz O, Bossone E, Bettio M, Pavan D, Carerj S, Antonini-Canterin F. Carotid artery stiffness and diastolic function in subjects without known cardiovascular disease. J Am Soc Echocardiogr, 2011; 24: 915-921.

16. Jaroch J, Łoboz Grudzień K, Bociaga $Z$ et al. The relationship of carotid arterial stiffness to left ventricular diastolic dysfunction in untreated hypertension. Kardiol Pol, 2012; 70: 223-231.

17. Magda SL, Ciobanu AO, Florescu M, Vinereanu D. Comparative reproducibility of the noninvasive ultrasound methods for the assessment of vascular function. Heart Vessels, 2012 Jan 13 (e-pub).

18. Grundy SM. Age as a risk factor: You are as old as your arteries. Am J Cardiol, 1999; 83: 1455-1457.

19. Eleid MF, Lester SJ, Wiedenbeck TL et al. Carotid ultrasound identifies high risk subclinical atherosclerosis in adults with low Framigham risk scores. J Am Soc Echocardiogr, 2010; 23: 802-808.

20. Naqvi TZ, Mendoza F, Rafii F et al. High prevalence of ultrasound detected carotid atherosclerosis in subjects with low Framingham risk score: potential implications for screening for subclinical atherosclerosis. J Am Soc Echocardiogr, 2010; 23: 809-815.

21. Gepner AD, Keevil JG, Wyman RA et al. Use of carotid intima media thickness and vascular age to modify cardiovascular risk prediction. J Am Soc Echocardiogr, 2006; 19: 1170-1174.

22. Salomaa V, Riley W, Kark JD, Nardo C, Folsom AR. Non-insulin-dependent diabetes mellitus and fasting glucose and insulin concentrations are associated with arterial stiffness indexes. The ARIC Study. Circulation, 1995; 91: 1432-1443.

23. Inglseder B, Cip P, Malaimare L, Ladurner G, Paulweber B. The metabolic syndrome is a stronger risk factor for early carotid atherosclerosis in women than in men. Stroke, 2005; 36: 1212-1217.

24. Lin HF, Liu CK, Liao YC, Lin RT, Chen CS, Juo SH. The risk of the metabolic syndrome on carotid thickness and stiffness: Sex and age specific effects. Atherosclerosis, 2010; 210: 155-159.

25. Zieman SJ, Melenovsky V, Kass DA. Mechanisms, pathophysiology, and therapy of arterial stiffness. Arterioscler Thromb Vasc Biol, 2005; 25: 932-943.

26. O'Rourke M. Mechanical principles in arterial disease. Hypertension, 1995; 26: 2-9.

27. Vermeersch SJ, Rietzschel ER, De Buyzere ML et al. Age and gender related patterns in carotid-femoral PWV and carotid and femoral stiffness in a large healthy middle-aged population. J Hypertens, 2008; 26: 1411-1419. 